\title{
Factors associated with the length of delay with tuberculosis diagnosis and treatment among adult tuberculosis patients attending at public health facilities in Gondar town, Northwest, Ethiopia
}

\author{
Selamsew Bogale ${ }^{1}$, Ermias Diro ${ }^{1}$, Atsede Mazengia Shiferaw ${ }^{2}$ and Melaku Kindie Yenit ${ }^{3 *}$
}

\begin{abstract}
Background: Early diagnosis and prompt treatment is essential for an effective tuberculosis (TB) control program. However, significant proportion of cases remains undiagnosed and untreated. Delay in diagnosis and treatment increases transmission. Hence, the study assessed the length of delay and associated factors with tuberculosis diagnosis and treatment among adults attending public health facilities in Gondar town, Northwest Ethiopia.

Method: An institution based cross-sectional study was conducted from February to May, 2016. A total of 296 adults who came to health facilities for treatment for pulmonary TB from February to May, 2016, were included in the study. Data were collected using a structured questionnaire through interviewing and record review, cleaned, coded, and entered into Epi-info version 3.5.3, and transferred into SPSS version 20.0 for further statistical analysis. A $p$-value of less than 0.05 at multiple linear regression analysis was considered statistically significant.

Result: The mean duration of the total delay (in days) for tuberculosis diagnosis and initiation of treatment was 41. 6 days $(S D=16.6)$. In this study, the mean duration of patient delay and the median health system delay were 33 . 9 days $(S D=14)$ and 5 days $(I Q R=4-7)$, respectively. Total delay for $T B$ diagnosis and treatment was shorter among HIV positive people ( $\beta$ :-12.62, 95\% Cl: $-20.72,-4.53)$. Longer patient delay was noted among rural dwellers ( $\beta$ : 8.0, $95 \%$ Cl: $5.26,10.75)$; increased household income ( $\beta:-0.006,95 \% \mathrm{Cl}:-0.008,-0.004)$ was associated with a shorter delay. Health system delay was positively associated with seeking care from more than one health care providers ( $\beta$ : $0.28,95 \% \mathrm{Cl}: 0.23,0.34)$ and seeking initial care from primary level health care facilities ( $\beta$ : $0.10,95 \%$ Cl: $0.07,0.13$ ).

Conclusion: In this study, the majority of patients faced delayed in seeking health care and continued as sources of infection. Longer days of delay for TB diagnosis and treatment were noted among rural residents, who seek health care from informal care providers, and receive initial care from primary level health care facilities. In contrast, the length of delay for TB diagnosis and treatment was shorter among HIV positive people and individuals with increased household income. Therefore, public awareness on the symptoms of tuberculosis and seeking health care early is essential. Moreover, early diagnosis and treatment, especially among the rural dwellers and the poor should be focused.
\end{abstract}

Keywords: Delay, TB diagnosis and treatment, Northwest Ethiopia, 2016

\footnotetext{
* Correspondence: melaku98@gmail.com

${ }^{3}$ Department of Epidemiology and Biostatistics, University of Gondar, 196,

Gondar, Ethiopia

Full list of author information is available at the end of the article
} 


\section{Background}

Tuberculosis (TB) remains a major public health problem throughout the world $[1,2]$. About one-third of the world's population is estimated to be infected with the bacilli and become at risk of developing active TB infection [2]. In 2014, about 9.6 million new TB cases and over 1.5 million deaths from the diseases were reported; 95\% of these deaths occurred in low and middle income countries. Africa is the region with the most burden of TB cases with an estimated prevalence of 281 all forms of TB cases per 100,000 inhabitants which is doubled of the global average of 133 cases per 100,000 [3, 4]. According to the global tuberculosis report most countries shows progress in reducing the burden of tuberculosis though it is not as targeted by the millennium development goal. Considering this unmet target and to transform the world, the international community develops a new agenda of ending TB epidemic by 2030 in the newly adopted Sustainable Development Goals [5].

Effective TB control program through early diagnosis and treatment is an essential strategy to decrease the burden of the disease $[2,6]$. Most of the risk of TB infection occurs between the contacts of the infectious cases and before the initiation of treatment [7-10]. Early screening of presumptive TB cases starting at the community, providing rapid diagnosis, and treating the cases early at health facilities reduces the risk of disease transmission as a result the reduction of time between the onset of symptoms and the initiation of treatment $[2,11]$. Thus individuals who had cough for two weeks or more are requested to go to health facilities for diagnosis and early treatment [12]. As one of the major tools to diagnose tuberculosis, direct microscopy is not only cost effective but also simple and capable of producing reliable result, within two consecutive days [13-15]. The National (Ethiopia) TB Control Program recommends collecting three sputum specimens for pulmonary TB (PTB), and that individual who have at least two smear positive results or a single smear positive result supported by radiographic abnormalities be classified as pulmonary smear positive $\left(\mathrm{PTB}^{+}\right)$. While those with three initial smears negative examinations but showed major symptoms of TB are confirmed by gene-xpert or culture $[16,17]$. However this, low case detection rate (CDR) in most nations resulting from patients' inability to seek health care at the onset of symptoms and the delay of diagnosis and treatment remain a challenge in TB control programs [3, 13, 18, 19].

Delays in seeking health care and in providing early diagnosis and treatment increases the risk of disease transmission, and subsequently leads to death. TB diagnosis and treatment are delayed when patients wait until long after the onset of symptom to seek care (patient delay), or when care providers take too long to diagnose and treat the patients who sought care (health system delay) [14]. The length of delay was significantly longer among low and middle income countries than in the developed nations. The longest total delay in TB diagnosis and treatment was noted in Afghanistan (356.0 days) [20]. In most studies conducted elsewhere, it was noted that patient delay was longer than health system delay [20-22]. A cross-sectional study among smear positive pulmonary TB patients in Afghanistan reported that patient delay (205 days) was longer than health system delay (151 days). In Nigeria, the median total delay, patient delay, and health system delay was 11,8 , and 3 weeks, respectively [21]. In Angola, the median total time that elapsed from the onset of symptoms to diagnosis was 45 days,while the median patient delay and health system delay was 30 and 7 days, respectively [22]. A cross sectional study in Chad reported that the median patient delay, system delay, and total delay were 15 , 36, and 57.5 days, respectively [23]. In Ethiopia, though there are regional variations in total delay in TB diagnosis and treatment, it generally ranged from 40-97 days [8, 24-28]. As demonstrated by various reports, delay in diagnosis and treatment is found to be affected by various factors, but it is mainly related to patients' health care seeking behavior and health system provision of prompt diagnosis and treatment [22, 25, 29, 30]. Among the various factors reported, residence [22, 26], type of health facility [22], and seeking care from other than health care providers [29-31] were associated with the delay for TB diagnosis and treatment.

Ethiopia ranks 10th among 22 high TB burden countries (HBCs) and the disease remains one of the leading causes of mortality and morbidity. According to the 2014 WHO report, the incidence and prevalence of all forms of TB cases were 224 and 211 per 100,000 populations, respectively. Though there has been some achievement in the process of reducing the incidence of tuberculosis as targeted in the Millennium Development Goal (MDG),, still one-third of the suspected cases are not detected and continue a source of TB infection [32, 33]. Therefore, to determine the length of delay in seeking health care, early diagnosis and initiation of treatment can improve the detection rate and will have further role in the success of TB control programs.

\section{Methods}

\section{Study setting and design}

An institution-based cross-sectional study was conducted among pulmonary TB patients, who started TB treatment from February to May, 2016. The study was conducted at public health facilities of Gondar town. The town has eight health centers and one referral hospital providing sputum smear examination and direct observed short course on TB treatment (DOTS) (Gondar Town Adminstration Health 
Office: Annual Report of Gondar Town Administration Health Office, unpublished).

Study participants, sample size and sampling procedure All bacteriologically confirmed pulmonary TB cases greater than 18 years of age who were on treatment at an intensive phase were the population under study. The sample size was calculated using the single population mean formula and by considering the following assumptions: 44 days mean time for total delay [34], a 95\% level of confidence, $5 \%$ margin of error, and $5 \%$ non-response rate. Thus, a minimum sample size of 311 was obtained. As a result, all eligible TB patients attending the selected public health facilities during the study period were included consecutively. However, to avoid over-counting, a reminder note was attached to the transfer sheet when a patient was transferred from one health facility to another.

\section{Data collection tools and procedure}

Data were collected using a pretested structured questionnaire which was developed from the WHO multi-country study designed to estimate the length of delay of TB treatment $[14,35]$. To maintain consistency, the questionnaire was first translated from English to Amharic (the native language of the study area) and retranslated to English by professional translators and public health experts. Data were collected by interviewing and record review. Nine data collectors and two supervisors were selected for the study. Two days' intensive training regarding the objective of the study, and confidentiality of information was given to data collectors and supervisors. Awareness was created regarding the objective of the study, and respondents were made aware that their responses would not affect the possible treatments they needed.

\section{Operational definitions}

Total treatment delays (TTD), the dependent variable was assessed according to the key dimensions of delays for TB diagnosis and treatment stated by WHO. The total delay for TB diagnosis and treatment was the sum of patient delay and health system delay. It was specifically defined as the time interval between the onset of a cough to the first visit to a physician or health center (patient delay), plus the health system delay, which is the interval between the first visit to the initiation of anti-TB treatment (Fig. 1) [14].

A bacteriologically confirmed TB case was referred to as a patient whose biological specimen is positive by smear microscopy or WRD (such as Xpert MTB/RIF) [36].

\section{Data processing and analysis}

Data were entered into Epi-info version 3.5.3 and exported to a statistical package for social sciences (SPSS) version 20 for further analysis. Data cleaning was done by running frequencies. Descriptive statistics, including frequencies and proportions were computed to summarize the variables. Linear regression model was used in the process. Variables with a $p$-value of less than 0.2 in the simple linear regression analysis were entered into the multiple linear regression analysis. A $p$-value of less than 0.05 at the multiple linear regression analysis was considered statistically significant.

\section{Results \\ Socio-demographic characteristics of TB patients}

A total of two hundred ninety-six adult TB patients were included in the study. The mean age $( \pm S D)$ of participants was 31.7 years $( \pm 10.1)$. Of the total study participants, $50.7 \%$ were females, $69.3 \%$ were urban dwellers, and $29.1 \%$ were illiterate. Most of the respondents (88.5\%) were Orthodox Christians and the rest $(9.8 \%$ and $1.7 \%$, respectively) were Muslims and other religions. Participants who had access to health facilities in $30 \mathrm{~min}$ of walking time were $61.8 \%$. More than half of the respondents had a monthly household income ranging between ETB 501-1000 [Table 1].

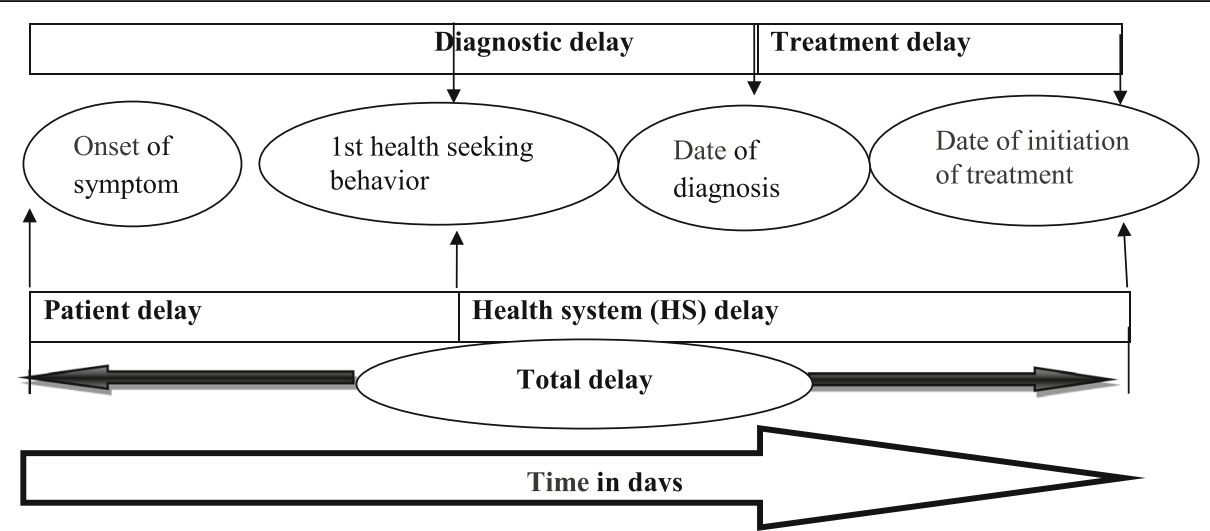

Fig. 1 Flow-chart showing different delay durations contributing to total delay (Source: WHO EMRO, Diagnostic and treatment delay in TB, 2006) 
Table 1 Socio-demographic characteristics of TB patients attending at public health facilities in Gondar town, Northwest Ethiopia, 2016

\begin{tabular}{lll}
\hline Variables & Frequency & Percent \\
\hline Sex & 146 & \\
Male & 150 & 49.3 \\
Female & & 50.7 \\
Age category (year) & 71 & \\
$18-24$ & 69 & 24 \\
$25-29$ & 51 & 23.3 \\
$30-34$ & 50 & 17.2 \\
$35-39$ & 33 & 16.9 \\
$40-44$ & 6 & 11.1 \\
$45-49$ & 71 & 2.0 \\
$\geq 50$ & & 24
\end{tabular}

Religion

Orthodox

262

88.5

Muslims

Others $^{\mathrm{a}}$

Ethnicity

Amhara

Kimant

Others $^{\mathrm{b}}$

Residence

Urban

Rural

Marital Status

Single

Married

Divorced

Others ${ }^{c}$

Educational status

No education
Read and write only
Primary School
Secondary School
College/University
Occupation
Un-employed
Self employed
Government employed
Private employed
Farmer
Student
Housewife

Household Income (ETB)
Table 1 Socio-demographic characteristics of TB patients attending at public health facilities in Gondar town, Northwest Ethiopia, 2016 (Continued)

\begin{tabular}{lll}
\hline$<500$ Birr & 68 & 23 \\
$501-1000$ Birr & 157 & 53 \\
$>1000$ & 71 & 24 \\
Time to reach health facility & & \\
$<30$ min & 183 & 61.8 \\
$30-60$ min & 58 & 19.6 \\
$>60$ & 55 & 18.6 \\
\hline${ }^{\text {PProtestant, }}{ }^{\text {b }}$ Tigre, Oromo, ${ }^{c}$ Widowed, Separated
\end{tabular}

Clinical and Behavioral Characteristics of respondents

About one-fifth $(20.3 \%)$ of the respondents had history of exposure to tuberculosis. Among the most common symptoms reported, a significant proportion of respondents $(88.9 \%, 72.6 \%$, and $72.6 \%$, respectively) had cough, fever and night sweat. More than one-third (33.1\%) did not consult health care providers as the first action during their symptoms. Most of the respondents perceived that the symptoms will go away on their own, and this was one of the reasons for the delay in diagnosis and treatment. Among the total 296 TB patients, about 228 cases were identified by sputum smear microscopy, while the rest, $68 \mathrm{~TB}$ cases were ascertained by genexpert. Twenty-four percent of the TB cases were coinfected with HIV [Table 2].

The behavioral characteristics of respondents indicated that most (99\%) knew the kind of disease they had at the time of interview. One-third (36.5\%) were aware that tuberculosis was not a hereditary disease, while only $10.1 \%$ knew that tuberculosis had a vaccine. More than half (54.1\%) knew how to prevent TB [Table 3].

\section{Length of delay in TB Diagnosis and Initiation of treatment}

In this study, the mean total days of delay for TB diagnosis and initiation of treatment were 41.6 (SD: 16.6). The minimum and maximum delay for $\mathrm{TB}$ diagnosis and treatment were 14 and 95 days, respectively. Longer days of delay in seeking health care were observed among patients. To be exact, the mean patient and the median health system delays were 33.9 (SD: 14) and 5 (IQR: 4, 7) days, respectively [Table 4].

The length of total delay was similar among male and female respondents, while it was longer among rural dwellers, and those who had below ETB 500 monthly income. The major perceived causes of delay of TB diagnosis and treatment for $74.3 \%, 16.9 \%$, and $5.1 \%$ of patients were reliance on mere hope that symptoms would clear up of their own accord, economic constraints, and imagined poor health care service, respectively [Fig. 2]. 
Table 2 Clinical characteristics of TB patients attending at public health facilities in Gondar town, Northwest Ethiopia, 2016

\begin{tabular}{|c|c|c|}
\hline Variables & Frequency & Percent \\
\hline \multicolumn{3}{|l|}{ Previous exposure to TB patient } \\
\hline Yes & 60 & 20.3 \\
\hline No & 236 & 79.7 \\
\hline \multicolumn{3}{|l|}{ HIV Status } \\
\hline Positive & 71 & 24 \\
\hline Negative & 225 & 76 \\
\hline \multicolumn{3}{|l|}{ First action with onset of symptoms } \\
\hline Consult Health Care Provider & 139 & 47 \\
\hline Practiced self-medication & 55 & 18.6 \\
\hline Visit traditional healers & 29 & 9.8 \\
\hline $\begin{array}{l}\text { Using non-prescribed medications from } \\
\text { Pharmacies }\end{array}$ & 73 & 24.7 \\
\hline \multicolumn{3}{|l|}{ Type of health facility first consultation } \\
\hline Health Post & 24 & 8.1 \\
\hline Health Center & 126 & 42.6 \\
\hline Governmental Hospital & 79 & 26.7 \\
\hline Private Clinic & 57 & 19.3 \\
\hline Private hospital & 10 & 3.4 \\
\hline \multicolumn{3}{|l|}{ No of Health Care Providers consulted } \\
\hline$\leq 2$ & 34 & 24.5 \\
\hline $3-4$ & 23 & 16.5 \\
\hline$\geq 5$ & 82 & 59.0 \\
\hline \multicolumn{3}{|l|}{ Reasons of First Consultation } \\
\hline Accessibility & 148 & 50 \\
\hline Confidence in getting Cured & 35 & 11.8 \\
\hline Service available anytime & 42 & 14.2 \\
\hline Better Care & 46 & 15.5 \\
\hline \multicolumn{3}{|l|}{ Smear Status } \\
\hline Smear Positive & 228 & 77 \\
\hline Smear Negative & 68 & 23 \\
\hline \multicolumn{3}{|l|}{ Investigation TB diagnosis made } \\
\hline Sputum smear microscopy & 228 & 77 \\
\hline Genexpert & 68 & 23 \\
\hline
\end{tabular}

\section{Factors associated with patient delay in seeking} tuberculosis diagnosis

In the multiple linear regression analysis, rural residence ( $\beta: 8,95 \% \mathrm{CI}: 5.26,10.75)$, and seeking care from informal providers at onset of symptoms ( $\beta: 8.09,95 \% \mathrm{CI}$ : $5.50,10.69)$ were factors associated with longer patient delays; while increased household income ( $\beta: 0.006,95 \%$ CI: $-0.008,-0.004)$, and HIV seropositivity ( $\beta: 8.9,95 \% \mathrm{CI}$ : $-12.02,-5.94)$ were associated with the shorter patient delays. This study specifically showed that patient delays among individuals who live in rural areas increased by 8 days compared with patients from urban settlements;
Table 3 comprehensive knowledge on tuberculosis among TB patients attending at public health facilities in Gondar town, Northwest, Ethiopia, 2016

\begin{tabular}{|c|c|c|}
\hline Knowledge items & Frequency & Percent \\
\hline \multicolumn{3}{|c|}{$\begin{array}{l}\text { Know the kind of disease } \\
\text { they have }\end{array}$} \\
\hline Yes & 293 & 99 \\
\hline \multicolumn{3}{|c|}{$\begin{array}{l}\text { Know tuberculosis is not } \\
\text { hereditary }\end{array}$} \\
\hline Yes & 108 & 36.5 \\
\hline \multicolumn{3}{|c|}{$\begin{array}{l}\text { Know tuberculosis is } \\
\text { contagious }\end{array}$} \\
\hline Yes & 290 & 98 \\
\hline \multicolumn{3}{|c|}{ Does tuberculosis curable } \\
\hline Yes & 283 & 95.6 \\
\hline \multicolumn{3}{|c|}{$\begin{array}{l}\text { Is tuberculosis vaccine } \\
\text { preventable }\end{array}$} \\
\hline Yes & 30 & 10.1 \\
\hline \multicolumn{3}{|c|}{$\begin{array}{l}\text { Know the duration of ant } \\
\text { tuberculosis treatment }\end{array}$} \\
\hline Yes & 253 & 85.5 \\
\hline \multicolumn{3}{|c|}{ Know TB prevention methods } \\
\hline Yes & 160 & 54.1 \\
\hline
\end{tabular}

individuals who seek care from informal care providers at onset of symptoms had 8.1 more days to seek health care for diagnosis, compared with those who seek health care from formal health care providers. The study also indicated that for a unit increase in household income (in Birr), patient delay decreased by 0.006 days, which means when a household income increased by ETB 1000 per month, patient delay decreased by 6 days. Individuals who were HIV positive sought health care nearly 9 days earlier than HIV negative individuals [Table 5].

Table 4 Types of delay of TB diagnosis and initiation of treatment among TB patients attending public health facilities of Gondar town, Northwest Ethiopia, 2016

\begin{tabular}{lll}
\hline Type of Delay & Value \\
\hline Patient Delay (days) & SD & 33.9 \\
& Min-Max & 14 \\
Health system Delay (days) & & $10-90$ \\
& Median & \\
& IQR & 5 \\
Total Delay (days) & Min-Max & $4-7$ \\
& & $3-30$ \\
& Mean & \\
& SD & 41.6 \\
Min-Max & 16.6 \\
\hline
\end{tabular}




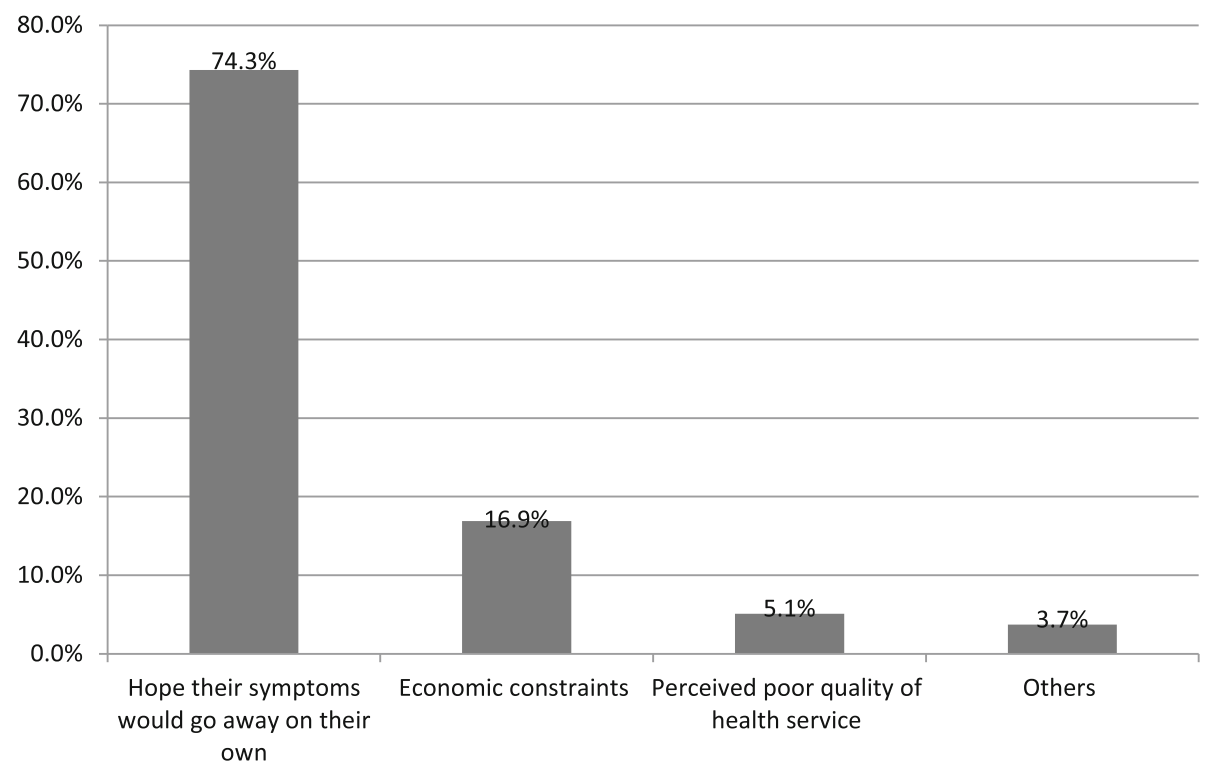

Fig. 2 Perceived causes of delay in health seeking health care among TB patients in public health institution of Gondar town, Northwest Ethiopia, 2016

Factors associated with delay in tuberculosis diagnosis and treatment at the health system

In the multiple linear regression analysis, longer health system delays were noted among respondents who sought care from more than one health care providers ( $\beta$ : $0.28,95 \%$ CI: $0.23,0.34)$ and primary level health care facilities ( $\beta$ : 0.10, 95\% CI: 0.07, 0.13) [Table 6].

\section{Factors associated with total delay in tuberculosis Diagnosis and treatment}

In the simple linear regression analysis, residence, educational status, household income, time to reach a health facility, HIV status, and seeking more than one health care provider were factors associated with total delays in tuberculosis diagnosis and treatment at a $p$-value of less than 0.2 . Consequently, these variables were subjected to multiple linear regression analysis, and it was noted that a longer delay of TB diagnosis and treatment was observed among rural residents ( $\beta$ : 10.3, 95\% CI: 2.911, $17.824)$, and those who seek health care from more than one health care providers ( $\beta$ : 7.674, 95\% CI: 2.972, $12.376)$, while increased household income ( $\beta:-0.008$, 95\% CI-0.013,-0.002 :) and HIV seropositivity ( $\beta:-12.62$, 95\% CI:-20.72,-4.525) were positively associated with shorter delays in diagnosis and treatment. Individuals from rural areas had ten extra days for TB diagnosis and treatment compared with individuals from urban areas. Similarly, household income was significantly associated with total delays of TB diagnosis and treatment. For a unit increase in household income in Birr, total delay decreased by 0.008 days, which means that as a household income increased by ETB 1000 per month, delay of TB diagnosis and treatment decreased by 8 days, and patients who were HIV positive had 12.6 shorter days for diagnosis and treatment compared with HIV negative individuals [Table 7].

\section{Discussion}

Ending TB epidemic by 2030 is among the health targets of the newly adopted Sustainable Development Goals

Table 5 Factors associated with patient delays among adult tuberculosis patients attending public health facilities of Gondar town, Northwest Ethiopia, 2016

\begin{tabular}{|c|c|c|}
\hline \multirow[t]{2}{*}{ Variables } & Simple Linear Regression & Multiple Linear Regression \\
\hline & $\beta(95 \% \mathrm{Cl})$ & $\beta(95 \% \mathrm{Cl})$ \\
\hline House hold income & $-0.009(-0.011,-0.006)$ & $-0.006(-0.008,-0.004)$ \\
\hline Rural residency & $9.88(6.58,13.19)$ & $8.00(5.26,10.75)$ \\
\hline HIV positive status & $-14.68(-18.04,-11.32)$ & $-8.97(-12.02,-5.94)$ \\
\hline seeking care from informal care providers ${ }^{a}$ & $11.19(8.22,14.16)$ & $8.09(5.50,10.69)$ \\
\hline
\end{tabular}

$B$ Beta coefficient

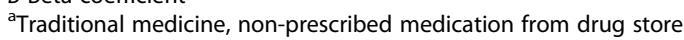


Table 6 Factor associated with health system delay among adult tuberculosis patients' attending public health facilities of Gondar town, Northwest Ethiopia, 2016

\begin{tabular}{lll}
\hline Variables & Simple Linear Regression & $\begin{array}{c}\text { Multiple Linear Regression } \\
\beta(95 \% \mathrm{Cl})\end{array}$ \\
\hline Age & $\beta(95 \% \mathrm{Cl})$ & - \\
Sex & $0.04(0.01,0.07)$ & - \\
Residency & $0.06(0.01,0.13)$ & - \\
HIV status & $0.14(0.08,0.21)$ & - \\
Seeking care from more than one health care provider & $-0.08(-0.16,-0.01)$ & $0.28(0.23,0.34)$ \\
Seeking initial care from primary level health care facilities & $0.30(0.23,0.38)$ & $0.10(0.07,0.13)$ \\
\hline
\end{tabular}

$B$ Beta coefficient

[5]. Cognizant of this initiative, early detection and prompt treatment of cases is the main strategy to reduce disease morbidity and mortality throughout the world [11]. In this study, total delay, patient and health system delays were measured to assess the length of delay in diagnosis and treatment.

In this study, mean total days of delay of TB diagnosis and treatment was 41.6 days (SD: 16.6). Out of the total 41.6 days of delay of diagnosis and treatment, the bulk of the days (33.9) of delay were patient delays. The length of delay in the health system of diagnosis and treatment was 5 days, which was significantly shorter than the patient delay. This reflects seeking health care for TB diagnosis and treatment takes longer time when compared with length of stay in the health system. In addition, it suggests that effort to increase awareness of the community to enhance seeking care to health care.

The total days of delay of TB diagnosis and treatment in this study (41.6 days) was in line with the studies conducted in Iraq (45 days) [37], and in Arsi Zone, Ethiopia (40 days) [8]. However, in this study total delay was lower than those of in studies in different regions of Ethiopia, Bale zone (97 days) [24], Afar (70.5 days) [25], Bahirdar (60 days) [26], Tigray (90 days), and East Wollega (90 days) [27, 28], and it was also lower than the findings of studies conducted in Nepal (50 days) [38], West Africa (60 days) [9], and Tanzania (120 days) [10].
The lower delay seen in this study compared with other studies might be that the majority of the participants of this study were urban dwellers who had access to better health care facilities, and the recent implementation of the Urban Health Extension Program in the study area. This suggests that effort should be made to expand and sustain these health care facilities in achieving the sustainable development goals and universal health coverage.

The finding revealed that the mean patient delay (standard deviation) was 33.9 (SD: 14) days. This finding was consistent with those of studies conducted in Ethiopia, for example Arsi Zone (22 days) [8], and Southern Ethiopia (30 days) [39], Tanzania and Zimbabwe (28 days each) [10, 40], Sudan (27 days) [41], and Thailand (30 days) [42], but it was longer than that of study conducted at Bahir Dar (21 days) [26]. On the other hand, the median health system delay (IQR) was 5 days (4-7). This finding was consistent with a report from Yemen (4 days) [37] and Arsi Zone (6 days) [8]. However, it was longer than the report from Zimbabwe (2 days) [40]. The longer health system delay in this study might be due to the turnover of experienced staff and the efficiency of health care professionals in identifying suspected cases [1, 43, 44]. Furthermore, shortage of resources of the TB control programs which was faced in most health facilities might be the reason for

Table 7 Factors associated with total delay of tuberculosis diagnosis and treatment among adult tuberculosis patients in public health facilities of Gondar town, Northwest Ethiopia, 2016

\begin{tabular}{lll}
\hline Variables & Simple Linear Regression & $\begin{array}{c}\text { Multiple Linear Regression } \\
\beta(95 \% \mathrm{Cl})\end{array}$ \\
\hline Educational status & $\beta(95 \% \mathrm{Cl})$ & - \\
First health care facility consulted & $-3.71(-5.13,-2.28)$ & - \\
Time to reach to the health facility & $4.69(3.28,6.11)$ & - \\
Rural residency & $0.25(0.19,0.29)$ & $10.3(2.91,17.82)$ \\
House hold income & $13.45(9.63,17.28)$ & $-0.008(-0.013,-0.002)$ \\
HIV status & $-0.009(-0.012,-0.007)$ & $-12.62(-20.72,-4.53)$ \\
Seeking care from more than one health care provider & $-17.236(-21.20,-13.26)$ & $7.674(2.97,12.37)$ \\
\hline
\end{tabular}


longer health system delays in TB diagnosis and treatment $[45,46]$.

Among factors which had significant associations with patient delays, patient delays among rural residents were longer by 8 days compared with urban residents. Consistent with studies elsewhere [28, 41, 47, 48], long delays among rural residents might be the inaccessibility of health care facilities. Similarly, the length of patient delay was longer among respondents who sought health care from informal care providers, which was consistent with studies conducted in Afar [25], Arsi Zone [8], and Uzbekistan [49]. In countries like Ethiopia where there are various traditional practices and poor access to quality health care, patient sough care from informal health care provider; as a result the patients might have been given inappropriate care which led to several other visits before reaching the appropriate health facility for $\mathrm{TB}$ care. In contrast, shorter patient delay was noted among HIV positive individuals compared with HIV negative ones. This association was similar with those of studies in Bahir Dar, Ethiopia [26], and Mozambique [31]. This might be due to the collaborative TB/HIV activities existing in the health institution which ensures early TB screening among HIV patients and vice versa [50]. In addition, strict follow-up of health care providers for HIV positive individuals might be the reason for shorter delay in seeking health care for TB diagnosis and treatment.

A shorter patient delay was reported among individuals with increased household income, which was consistent with a finding in Sudan [41]. This might be due to the role of income in enhancing the chance of seeking health care. Consistent with studies conducted elsewhere $[8,24,40,51]$, a longer health system delay was noted among individuals who seek care from more than one health care providers. Similarly, the length of health system delay was longer among individuals who sought initial care from primary level health facilities which was similar with those of studies conducted in Nigeria [21] and different regions of Ethiopia, like Arsi Zone, Bahir Dar, and Bale zone $[8,24,26]$.

As a limitation, recalling the exact date of the onset of symptoms and the date of visits to health facilities might under or overestimate the delay. However, to minimize such bias reviews of medical records, national holidays, religious days, and dates of some events were put to use. The other limitation of this study, patient related factors in the health system delay, was not assessed.

\section{Conclusion}

The delay of tuberculosis diagnosis and treatment in this study was longer than the national recommendation of two weeks (14 days). Seeking health care for diagnosis was responsible for longer delays. Longer delay of $\mathrm{TB}$ diagnosis and treatment were noted among rural residents, patients who sought health care from informal care providers, and those who received initial care from primary level health care facilities. In contrast, the delay of TB diagnosis and treatment was shorter among HIV positive people and individuals with increased household income. Therefore, public awareness on the symptoms of tuberculosis and seeking early care is essential. Moreover, early detection, follow-up, and initiation of TB treatment among people living in rural areas and among the poor should be focused on.

\section{Abbreviations \\ CDR: Case detection rate; Cl: Confidence interval; DOTs: Directly observed treatment short-course; ETB: Ethiopian birr; HBCs: High burden countries; HIV: Human immunodeficiency virus; HS: Health system; IQR: Inter quartile range; MDG: Millennium development goal; MDR-TB: Multi drug resistant tuberculosis; MTB: Mycobacterium tuberculosis; PTB+: Smear-positive pulmonary tuberculosis; SD: Standard deviation; SPSS: Statistical software for social science; TB: Tuberculosis; TTD: total treatment delay; WHO: World Health Organization; WRD: WHO-endorsed Rapid Diagnostics}

\section{Acknowledgments}

The authors are indebted to the University of Gondar for the approval of the ethical clearance and for their technical support of this study, the University of Gondar Hospital and Gondar town administration health office for giving us permission to collect the data in the health facilities. The authors also forward its gratitude to patients, data collectors, and supervisors who participated in the study.

\section{Funding}

No specific funding was obtained for this study.

Availability of data and materials

Data will be available upon request from the correspondence authors.

\section{Authors' contributions}

SB Conceived of the study, coordinated data collection, performed statistical analysis and drafted the manuscript. ED, AMS, and MKY performed statistical analysis, and drafted the manuscript. All authors read and approved the final manuscript.

\section{Competing interest}

Authors declare that they have no any conflict of interest.

\section{Consent for publication}

Not applicable for this study.

\section{Ethics approval and consent to participate}

Ethical clearance was obtained from the Institutional Review Board of the University of Gondar. An official permission letter was obtained from Gondar university hospital CEO and Gondar town administration health office and written informed consent from each study participants. The right of participants to withdraw from the study at any time, without any precondition was disclosed unequivocally. Moreover, Privacy and confidentiality of information were strictly guaranteed by all data collectors and investigators by using code numbers rather than personal identifiers, and by keeping the questionnaire locked. The information retrieved was only used for the study purpose.

\section{Author details}

${ }^{1}$ Department of Internal medicine, University of Gondar, Gondar, Ethiopia. ${ }^{2}$ Department of Health Informatics, University of Gondar, Gondar, Ethiopia. ${ }^{3}$ Department of Epidemiology and Biostatistics, University of Gondar, 196, Gondar, Ethiopia. 


\section{Received: 13 October 2016 Accepted: 2 February 2017}

\section{Published online: 14 February 2017}

\section{References}

1. Marinucci F, Majigo M, Wattleworth M, Paterniti AD, Hossain MB, Redfield R. Factors affecting job satisfaction and retention of medical laboratory professionals in seven countries of Sub-Saharan Africa. Human Resour Health. 2013;11(1):1.

2. Organization WH. Global Tuberculosis Control 2010. Geneva: WHO; 2010.

3. Federal Democratic Republic of Ethiopia MoH: Guidelines for clinical and programmatic management of TB, leprosy and TB/HIV in Ethiopia. In., Fifth edition edn; April, 2012. https://www.medbox.org/guidelines-for-clinicaland-programmatic-management-of-tb-tbhiv-and-leprosy-in-ethiopia/ download.pdf.

4. Federal Democratic Republic of Ethiopia MoH. Ethiopian Public Heath Institute: Implementation Guideline for GeneXpert MTB/RIF Assay in Ethiopia. Addis Ababa. In. 2014.

5. Sachs JD. From millennium development goals to sustainable development goals. Lancet. 2012;379(9832):2206-11.

6. Uplekar M, Figueroa-Munoz J, Floyd K, Getahun H, Jaramillo E: The Stop TB Strategy: building on and enhancing DOTS to meet the TB-related Millennium Development Goals. POPLINE 2006.

7. Organization WH. Global tuberculosis report 2013. World Health Organization; 2013

8. Hamza A, Demissie M, Gare S, Teshome G. Delay in Tuberculosis Diagnosis among Tuberculosis Patients at the Three Hospitals: Asella, Robe and Abomsa of Arsi Zone, Oromia Regional State. Open Access Libr J. 2015;2(12):e1947.

9. Lienhardt C, Rowley J, Manneh K, Lahai G, Needham D, Milligan P, McAdam K. Factors affecting time delay to treatment in a tuberculosis control programme in a sub-Saharan African country: the experience of The Gambia. Int J Tuberc Lung Dis. 2001;5(3):233-9.

10. Wandwalo E, Mørkve O. Delay in tuberculosis case-finding and treatment in Mwanza, Tanzania. Int J Tuberc Lung Dis. 2000;4(2):133-8.

11. Pio A. Toman's tuberculosis: case detection, treatment, and monitoring. Bull World Health Organ. 2005;83(5):397-8.

12. Ethiopia MoHo: Tuberculosis, Leprosy and TB/HIV Prevention and Control Programme manual. 2008. http://www.who.int/hiv/pub/guidelines/ethiopia_tb.pdf.

13. Organization WH. Treatment of tuberculosis: guidelines. World Health Organization; 2010.

14. Organization WH. Diagnostic and treatment delay in tuberculosis. 2006.

15. Organization WH. World Health Organization global tuberculosis report. Online available at: http://www.who int/tb/publications/global_report/ gtbr12_main pdf. 2013.

16. $\mathrm{MOH}$. Tuberculosis, leprosy and TB/HIV prevention and control programme. MANUAL. 4th Edition. Addis Ababa. 2008. http://www.who.int/hiv/pub/ guidelines/ethiopia_tb.pdf. Accessed 12 Aug 2014.

17. Ethiopia MoHo. Tuberculosis, Leprosy and TB/HIV Prevention and Control Programme manual; 2008.

18. Organization WH. Global tuberculosis report 2013: World Health Organization; 2013.

19. Group CGTW. Community-Based Tuberculosis Prevention and Care: Why — and How — to Get Involved. In: An International Handbook for Nongovernmental Organizations and Civil Society Organizations. Washington: CORE Group; 2013.

20. Sabawoon W, Sato H, Kobayashi Y. Delay in the treatment of pulmonary tuberculosis: a report from Afghanistan. Environ Health Prev Med. 2012; 17(1):53-61.

21. Ukwaja KN, Alobu I, Nweke CO, Onyenwe EC. Healthcare-seeking behavior, treatment delays and its determinants among pulmonary tuberculosis patients in rural Nigeria: a cross-sectional study. BMC Health Serv Res. 2013;13:1.

22. Lusignani LS, Quaglio G, Atzori A, Nsuka J, Grainger R, Palma MDC, Putoto G, Manenti F. Factors associated with patient and health care system delay in diagnosis for tuberculosis in the province of Luanda, Angola. BMC Infect Dis. 2013;13:1

23. Ngangro NN, Ngarhounoum D, Ngangro MN, Rangar N, Siriwardana MG, des Fontaines VH, Chauvin P. Pulmonary tuberculosis diagnostic delays in Chad: a multicenter, hospital-based survey in Ndjamena and Moundou. BMC Public Health. 2012;12:1

24. Hussen A, Biadgilign S, Tessema F, Mohammed S, Deribe K, Deribew A. Treatment delay among pulmonary tuberculosis patients in pastoralist communities in Bale Zone, Southeast Ethiopia. BMC Res Notes. 2012;5:1.
25. Belay M, Bjune G, Ameni G, Abebe F. Diagnostic and treatment delay among Tuberculosis patients in Afar Region, Ethiopia: a cross-sectiona study. BMC Public Health. 2012;12:1.

26. Yimer SA, Bjune GA, Holm-Hansen C. Time to first consultation, diagnosis and treatment of TB among patients attending a referral hospital in Northwest, Ethiopia. BMC Infect Dis. 2014;14:1.

27. Mesfin MM, Tasew TW, Tareke IG, Kifle YT, Karen WH, Richard MJ. Delays and care seeking behavior among tuberculosis patients in Tigray of northern Ethiopia. Ethiop J Health Dev. 2005;19(l):7.

28. Wondimu T, Kassahun W, Getachew S. Delay in initiating tuberculosis treatment and factors associated among pulmonary tuberculosis patients in East Wollega, Western Ethiopia. Ethiop J Health Dev. 2007;21(2):148-56.

29. Yimer S, Bjune G, Alene G. Diagnostic and treatment delay among pulmonary tuberculosis patients in Ethiopia: a cross sectional study. BMC Infect Dis. 2005;5:112.

30. Makwakwa L, Sheu M-I, Chiang C-Y, Lin S-L, Chang PW. Patient and health system delays in the diagnosis and treatment of new and retreatment pulmonary tuberculosis cases in Malawi. BMC Infect Dis. 2014;14:1.

31. Saifodine A, Gudo PS, Sidat M, Black J. Patient and health system delay among patients with pulmonary tuberculosis in Beira city, Mozambique. BMC Public Health. 2013;13:1.

32. Organization WH: Ethiopia- update Sheet on TB program In., March 2015 edn. Addis Ababa, Ethiopia; 2014. http://www.afro.who.int/index. php?option=com_docman\&task=doc_download\&gid=9641\&ltemid=2593.

33. WH Organization. World Health Organization global tuberculosis control. Geneva: World Health Organization; 2011.

34. Asefa A, Teshome W. Total delay in treatment among smear positive pulmonary tuberculosis patients in five primary health centers, southern Ethiopia: a cross sectional study. PloS one 2014;9(7):e102884.

35. Bassili A, Seita A, Baghdadi S, AlAbsi A, Abdilai I, Agboatwalla M, Maamari F, Nasehi M, Nasir H, Soliman S. Diagnostic and treatment delay in tuberculosis in 7 countries of the Eastern Mediterranean Region. Infect Dis Clin Pract. 2008;16(1):23-35.

36. Organization WH: Definitions and reporting framework for tuberculosis-2013 revision. In. Geneva; 2013. http://www.who.int/iris/handle/10665/79199.

37. Organization WH. Diagnostic and treatment delay in tuberculosis. 2006. http:// www.who.int/iris/handle/10665/116501.

38. Choudhari M, Jha N, Yadav D, Chaudhary D. Factors associated with patient delay in diagnosis of pulmonary tuberculosis in a district. J Nepal Health Res Coun. 2013; 10(22):234-38.

39. Asefa A, Teshome W. Total delay in treatment among smear positive pulmonary tuberculosis patients in five primary health centers, Southern Ethiopia: a cross sectional study. PLoS One. 2014;9(7):e102884.

40. Takarinda KC, Harries AD, Nyathi B, Ngwenya M, Mutasa-Apollo T, Sandy C Tuberculosis treatment delays and associated factors within the Zimbabwe national tuberculosis programme. BMC Public Health. 2015;15:1.

41. Mohamed E, Abdalla S, Khamis A, Abdelbadea A, Abdelgadir M. Factors associated with patient delay in accessing pulmonary tuberculosis care, Gezira State, Sudan, 2009/Facteurs associés au retard d'accès des patients au traitement de la tuberculose pulmonaire dans l'État de Gezira (Soudan) en 2009. East Mediterr Health J. 2013;19(2):114.

42. Rattananupong T, Hiransuthikul N, Lohsoonthorn V, Chuchottaworn C. Factors associated with delay in tuberculosis treatment at ten tertiary level care hospitals in Thailand. Southeast Asian J Trop Med Public Health. 2015;46(4):689-96.

43. Yami A, Hamza L, Hassen A, Jira C, Sudhakar M. Job satisfaction and its determinants among health workers in jimma university specialized hospital, southwest ethiopia. Ethiop J Health Sci. 2011;21(3).

44. Abera E, Yitayal M, Gebreslassie M. Turnover Intention and Associated Factors among Health Professionals in University of Gondar Referral Hospital, Northwest Ethiopia. Int J Econ Manag Sci. 2014;3(4):1-11.

45. Tadesse T, Demissie M, Berhane Y, Kebede Y, Abebe M. Long distance travelling and financial burdens discourage tuberculosis DOTs treatment initiation and compliance in Ethiopia: a qualitative study. BMC Public Health. 2013;13:1.

46. Castelnuovo B. Review of compliance to anti tuberculosis treatment and risk factors for defaulting treatment in Sub Saharan Africa. Afr Health Sci. 2010;10(4).

47. Cambanis A, Yassin MA, Ramsay A, Bertel Squire S, Arbide I, Cuevas LE. Rural poverty and delayed presentation to tuberculosis services in Ethiopia. Trop Med Int Health. 2005;10(4):330-5.

48. Mahendradhata Y, Syahrizal BM, Utarini A. Delayed treatment of tuberculosis patients in rural areas of Yogyakarta province, Indonesia. BMC Public Health. 2008;8:1. 
49. Belkina TV, Khojiev DS, Tillyashaykhov MN, Tigay ZN, Kudenov MU, Tebbens $J \mathrm{D}$, Vlcek J. Delay in the diagnosis and treatment of pulmonary tuberculosis in Uzbekistan: a cross-sectional study. BMC Infect Dis. 2014;14:1.

50. Getahun H, Van Gorkom J, Harries A, Harrington M, Nunn P. Interim policy on collaborative TB/HIV activities. POPLINE 2004.

51. Osei E, Akweongo P, Binka F. Factors associated with DELAY in diagnosis among tuberculosis patients in Hohoe Municipality, Ghana. BMC Public Health. 2015;15:1.

Submit your next manuscript to BioMed Central and we will help you at every step:

- We accept pre-submission inquiries

- Our selector tool helps you to find the most relevant journal

- We provide round the clock customer support

- Convenient online submission

- Thorough peer review

- Inclusion in PubMed and all major indexing services

- Maximum visibility for your research

Submit your manuscript at www.biomedcentral.com/submit 